\title{
Resveratrol reduces myofibroblast arrhythmogenicity
}

\author{
Christian Rosker, Nicolò Salvarani, Stephan Rohr \\ From 16th Scientific Symposium of the Austrian Pharmacological Society (APHAR) \\ Vienna, Austria. 25-27 November 2010
}

\section{Background}

Among grape skin polyphenols, trans-resveratrol (RES) has been reported to slow the development of cardiac fibrosis and to affect myofibroblast (MFB) differentiation. Because MFBs induce slow conduction and ectopic activity following heterocellular gap junctional coupling to cardiomyocytes, we investigated whether RES and its main metabolites affect arrhythmogenic cardiomyocyteMFB interactions.

\section{Methods}

Experiments were performed with patterned growth strands of neonatal rat ventricular cardiomyocytes coated with cardiac MFBs. Impulse propagation characteristics were measured optically using voltage-sensitive dyes. Long-term video recordings served to characterize drug-related effects on ectopic activity. Data are given as means \pm S.D. $(n=4-20)$.

\section{Results}

Exposure of pure cardiomyocyte strands to RES at concentrations up to $10 \mu \mathrm{mol} / \mathrm{L}$ had no significant effects on impulse conduction velocity $(\theta)$ and maximal action potential upstroke velocities $\left(\mathrm{dV} / \mathrm{dt}_{\max }\right)$. By contrast, in MFB-coated strands exhibiting slow conduction, RES enhanced $\theta$ with an $\mathrm{EC}_{50}$ of $\sim 10 \mathrm{nmol} / \mathrm{L}$ from $226 \pm 38$ to $344 \pm 24 \mathrm{~mm} / \mathrm{s}$ and $\mathrm{dV} / \mathrm{dt}_{\max }$ from $48 \pm 7$ to $69 \pm$ $2 \% \mathrm{APA} / \mathrm{ms}$, i.e., to values of pure cardiomyocyte strands $(347 \pm 33 \mathrm{~mm} / \mathrm{s} ; 75 \pm 4 \% \mathrm{APA} / \mathrm{ms})$. Moreover, RES led to a reduction of ectopic activity over the course of several hours in heterocellular preparations. RES is metabolized quickly in the body; therefore, we tested the main known metabolites for functional effects and found them similarly effective in normalizing conduction with

*Correspondence: rosker@pyl.unibe.ch

Department of Physiology, University of Bern, 3012 Bern, Switzerland
$\mathrm{EC}_{50} \mathrm{~S}$ of $\sim 10 \mathrm{nmol} / \mathrm{L}$ (3-OH-RES), $\sim 20 \mathrm{nmol} / \mathrm{L}$ (RES-3$\mathrm{O}-\beta$-glucuronide) and $\sim 10 \mathrm{nmol} / \mathrm{L}$ (RES-sulfate), respectively. At these concentrations, neither RES nor its metabolites had any effects on MFB morphology and $\alpha$-smooth muscle actin expression. This suggests that the antiarrhythmic effects observed were based on mechanisms different from a change in MFB phenotype.

\section{Conclusions}

The results demonstrate that RES counteracts MFBdependent arrhythmogenic slow conduction and ectopic activity at physiologically relevant concentrations. Because RES is rapidly metabolized following intestinal absorption, the finding of equal antiarrhythmic effectiveness of the main RES metabolites warrants their inclusion in future studies of potentially beneficial effects of these substances on the heart.

Published: 16 November 2010

doi:10.1186/1471-2210-10-S1-A3

Cite this article as: Rosker et al:: Resveratrol reduces myofibroblast arrhythmogenicity. BMC Pharmacology 2010 10(Suppl 1):A3.

Submit your next manuscript to BioMed Central and take full advantage of:

- Convenient online submission

- Thorough peer review

- No space constraints or color figure charges

- Immediate publication on acceptance

- Inclusion in PubMed, CAS, Scopus and Google Scholar

- Research which is freely available for redistribution 